Volume 8, No.5, September - October 2019

International Journal of Advanced Trends in Computer Science and Engineering

Available Online at http://www.warse.org/IJATCSE/static/pdf/file/ijatcse37852019.pdf

https://doi.org/10.30534/ijatcse/2019/37852019

\title{
A Novel Leach Routing Protocol using Genetic Algorithm for Wireless Sensor Networks
}

\author{
Amer O. Abu Salem \\ Information Technology College, Zarqa University-Jordan \\ abusalem@zu.edu.jo
}

\begin{abstract}
Wireless sensor networks typically consist of a large number of small low-cost electronic devices with limited capacities to collect information from a given range of interest. Thus, the lifetime of a network is affected, and energy consumption increases. This paper aims mainly to activate the node and reduce energy consumption in order to transmit or receive the information from the sensor nodes. The paper considers three variables, such as residual energy, distance from the sink node, node density to select as a cluster head based on a genetic algorithm.
\end{abstract}

Key words : Leach protocol, Cluster-Head Selection Approach, Genetic algorithm.

\section{INTRODUCTION}

At current, the Wireless Sensor Networks (WSNs) are emerging as a promising and pleasant region; they have expanded the limits of our globe. The WSNs are a compact, relatively tinny computational node mixture and tiny, randomly dispersed devices. The WSN is mostly a network of nodes that allows communication between people and computers.

The homogeneity of the nodes, the scalability of the network, the capacity to resist severe environmental circumstances and to deal with node failures are some of the features that keep the network sensor technology above all other techniques. Sensor nodes interact with each other using radio signals and are deployed to detect, track and comprehend the physical universe. Once the nodes have been deployed, they provide long-term services without having to change or reload them. There are tasks for WSNs such as the ability to monitor physical and environmental conditions, such as light, temperature, humidity and pressure, overwhelmingly in realtime. The ability to operate equipment such as engine switches or actuators controlling those circumstances; and the ability to deliver effective and reliable communications through a wireless network [1].

The sensors are connected to the nodes measure ambient situations relevant to the environment in which they are deployed, process the data and transmit them to the sink node ( $\mathrm{SN}$ ). In addition, sensor nodes are equipped with a radio transceiver or other wireless communications equipment, a limit energy source, and finally a small microcontroller[2].

Sensor nodes are generally constrained with limited energy, hence limitation of the energy source is the most challenging in WSNs [3], and energy has an important function in most applications. The primary demands of a WSN are shown in Figure 1.

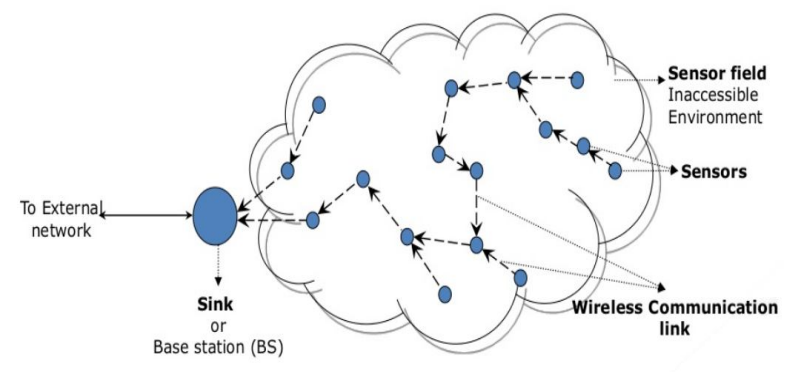

Figure 1: Wireless Sensor Network

Subsequently, we need to develop a routing protocol to reduce the energy consumption of each node; several routing protocols are designed and developed to achieve this goal. In common, routing in WSNs can be split into location-based, hierarchical, and flat routing. One of the hierarchical routing protocols is the Low Energy Adaptive Clustering Hierarchy (LEACH) protocol, it is the easiest routing protocol, and its primary aim is to extend the lifetime of the network by equally distributing the energy load between all the sensor nodes in the network. The emphasis of the manuscript is on improving power consumption in the network of wireless sensors. It involves two energy improvement methodologies such as LEACH and genetic algorithm.

The document maintains energy proficiency difficulty. LEACH protocol is the primary decorum of hierarchicalrouting that introduces the facts blending. This paper contains a long evaluation of the work-study, which demonstrates the competent methods for the recovery of the power failure. The paper presents a descriptive note on the literature review, along with the methodologies used to improve the power consumption of wireless sensor networks. 


\section{LITERATURE REVIEW}

Various research projects considered LEACH to be the best protocol to save power and extend the life of WSN. The versions from $\mathrm{LEACH}$, therefore, benefit from the LEACH features and reduce their disadvantages. LEACH-C[4][5] is a series of LEACH protocols in which every node location is a critical data that can be used by BS to organize the clusters for the current round.

A cluster head $(\mathrm{CH})$ is chosen to represent the most suitable nodes and non- $\mathrm{CH}$ nodes are distributed as cluster member nodes. In comparison to traditional LEACH, the first dead node metric enhancement has happened with LEACH-C, but the LEACH-C is not suitable for large scale networks.

Multi-hop LEACH [ 6 ] suggested for handling loads of energy. Every node is immobile and BS has been fixed. The selection method for $\mathrm{CH}$ is randomly selected. Multihop technology helps to reduce the complete consumption of energy. When one or more intermediate $\mathrm{CHs}$ are dead or failed, critical problem is indicated.

LEACH-GA [7] protocol is a scheme for grouping genetic algorithms. In perspective of the optimal rates of $\mathrm{CH}$ to BS, each node sends its node identity, zone information and $\mathrm{CH}$ selection. The BS uses genetic calculations to detect the ideal limit probability on obtained data and to communicate it for groups. The extra overhead for calculating the desired percentage of $\mathrm{CHs}$ is produced.

\section{METHODOLOGY}

The section consists of increasing the life span of the device node via various routing strategies. The theoretical techniques and standard algorithms are explained in this paper. This research concludes by improving the service life and power usage of the sensor nodes wireless sensor networks, by implement multi scenarios of simulation to evaluate the performance of three protocols compared with the proposed strategy. Having investigated the most significant application types, the key evaluation metrics for WSNs can be summarized into lifetime, coverage, cost and ease of deployment, response time, temporal accuracy, security and effective sample rate, some of them will be used in this research.

\section{WIRELESS SENSOR NETWORKS}

Wireless sensor networks consist of nodes with restricted energy and memory that help to monitor the remote regions that are not reached by humans. The created network is spread over a big region for monitoring the environment for pressures, conditions of sound and temperature and for collaborative communication of the information to other places via the network. The four fundamental segments in the sensor hub as shown in Figure 2 are a sensor unit, a processing unit, a transceiver and a power unit. The sensor unit has added two segments: at least one sensor and an ADC [8].

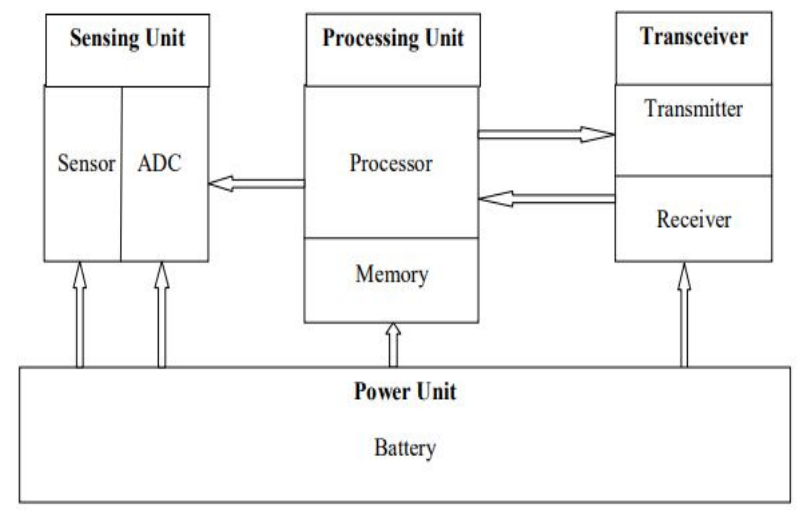

Figure 2: Block diagram of a sensor

\section{LEACH PROTOCOL}

The main objective of hierarchical routing protocols is to efficiently maintain the energy consumption of sensor nodes through participating them in multi-hop communication within a specific cluster and through performing data collection and incorporation in order to decrease the number of transmitting messages to the SN as shown in Figure 3. Cluster formation usually depends on the energy reserve of sensors and sensor's vicinity to the $\mathrm{CH}$.

LEACH is the first hierarchical routing protocols for sensor networks. The main idea proposed in the LEACH protocol has been a revelation for many hierarchical routing protocols. It is also the most widespread hierarchical routing protocols.

The basic idea of LEACH protocol is based on the cluster mechanism. A distributed algorithm is used to compose clusters, nodes adopt autonomous decisions to form clusters. Also, there is no centralized control on nodes for clustering, and nodes adopt autonomous decisions to form clusters. In LEACH protocol nodes are randomly distributed in the sensing field with the ability to collect and process the data. LEACH protocol divides into several rounds, shown in Figure 3, which is moreover divided into two phases [9]:

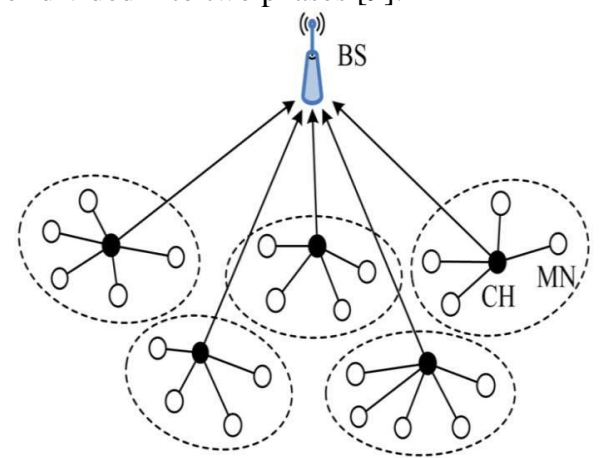

Figure 3: Architecture of LEACH Protocol

Phase One: Set-Up Phase :

The setup phase follows the below series:

1. Cluster Head Selection: each round starts with a $\mathrm{CH}$ selection, every node in the network determines whether to become the $\mathrm{CH}$ for the current round or not. Based on the needed percentage of $\mathrm{CHs}$ for the network and the number of times the node has been a $\mathrm{CH}$. For each node 
$\mathrm{n}$, the equation of the threshold for $\mathrm{CH}$ selection is given as following [10] :

$$
\begin{gathered}
\mathbf{T}(\mathbf{n})=\frac{\mathbf{H}}{\mathbf{1}-\mathbf{N} *\left(\operatorname{rmod}\left(\frac{1}{\mathbf{H}}\right)\right)} \quad \forall \mathbf{n} \in \mathbf{G} \\
\mathbf{T}(\mathbf{n})=\mathbf{0} \quad \text { otherwise }
\end{gathered}
$$

Where $\mathrm{n}$ is random number, $\mathrm{H}$ is Cluster Head probability, $\mathrm{T}(\mathrm{n})$ is threshold Value. If the energy value is greater than the threshold value then the node becomes cluster-head. Every node in $\mathrm{G}$ selects a random number between 0 and 1 , then if the number is less than or equal to the threshold value, it is selected as the $\mathrm{CH}$ for the current round. While $\mathrm{CH}$ has been chosen successfully, it broadcasts an advertisement message to other sensor nodes as shown in Figure 4.

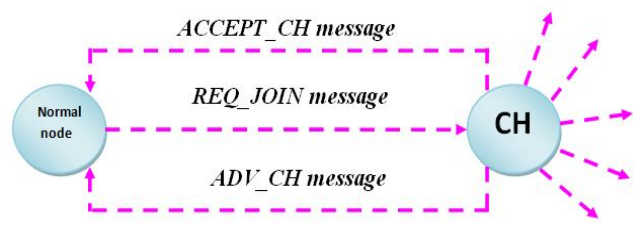

Figure 4: Procedure of Joins of Normal Node to $\mathrm{CH}$

The decision of nodes to join with $\mathrm{CH}$ based on the received signal strength of the advertisement, the nodes determine to which cluster it will join in the current round and send a membership message to its $\mathrm{CH}$. Now cluster formation is accomplished.

2. Cluster Formation: the moment that the $\mathrm{CHs}$ have been chosen, they advertise themselves to the remaining nodes. Depending on the signal strength, the nodes decide which cluster to join.

3. Transmission Schedule Creation: depending on the number of nodes in the cluster, the $\mathrm{CH}$ apportions different time slots for each node to transmit by adopting the basic time division multiple accesses (TDMA) scheduling.

\section{Phase Two: Steady State Phase}

Pending the steady-state phase, regular nodes aggregate the data then send it to its responsible $\mathrm{CH}$. The steady phase is divided into frames where nodes send their data to the $\mathrm{CH}$ at most once per frame through their allocated transmission slot $\mathrm{CH}$ received data from the sensor node that is in the same cluster, then it will aggregate data and send it to the SN. LEACH increases the network lifetime by using the resources in an efficient way, distributing the load uniformly, aggregating data at the $\mathrm{CH}$ to consist of only significative information, rotating the $\mathrm{CH}$ randomly to accomplish balance in energy consumption.

\section{GENETIC ALGORITHM FOR CLUSTER HEAD-VICE SELECTION}

The idea of the proposed scheme is concerned with a series of improvements, initially thinking about improving the LEACH protocol through selecting another node based on high residual energy to be as vice

for $\mathrm{CH}$, which will take the role of $\mathrm{CH}$ when $\mathrm{CH}$ dies. Then the protocol is improved through merging two issues included in the $\mathrm{CH}$ selection mechanism issue and routing issue, and both of these issues are basically affected on LEACH.

In the first issue, the idea is to reach an effective mechanism for choosing the $\mathrm{CH}$, the $\mathrm{CH}$ has several tasks and its responsible about all nodes in its cluster, then the selection of $\mathrm{CH}$ must be done depending on the deliberate and important factors, which will enable us to reduce energy consumption. In general if the selection is relying on more than one factor; then we need to determine the importance of each factor. In our case we need an appropriate and effective algorithm to optimize weighting for residual energy and the distance from sink node, which provides our purposes, to solve this problem. It has been resorting to a Genetic Algorithm (GA). The second issue concerns the selection of a vice for $\mathrm{CH}$.

Based on GA, the weight values of the two influencing factors, high current residual energy of each node, and the distance from $\mathrm{SN}$ are used as its optimization variable, with the presence of the vice of $\mathrm{CH}$, which will play as $\mathrm{CH}$ when $\mathrm{CH}$ dies. The maximum lifetime of First Dead Node (FDN) when the first node in the whole network runs out of energy. Half Dead Nodes lifetime (HDN) when $50 \%$ of the network nodes run out of the energy and stop operating and residual energy after both of them are used as the optimization objective.

\section{SIMULATION EVALUATION}

The network environment of the proposed protocol contains the parameters that are presented in the following Table 1. The simulator evaluating the performance of three protocols, in terms of their FDN \& HDN of WSN lifetime and their residual energy after FDN \& HDN, which is related to the consequence of their energy consumption. The comparison is between the following protocols with their assumption:

- LEACH-G: is proposed based on GA, the weight values of the three influencing factors, current residual energy of each node, the density of nodes and the distance from $\mathrm{SN}$ are used as its optimization variable. The maximum lifetime of the FDN \& HDN is used as the optimization objective.

- LEACH-V: it is an improved LEACH protocol of. It has the same assumption and objective of LEACH protocol, but with the presence of the vice of $\mathrm{CH}$, which will play as $\mathrm{CH}$ when $\mathrm{CH}$ dies.

- LEACH-GV: it is also proposed based on GA, the weight values of the two influencing factors, high current residual energy of each node, and the distance from $\mathrm{SN}$ are used as its optimization variable, with the presence of the vice of $\mathrm{CH}$, which will play as $\mathrm{CH}$ when $\mathrm{CH}$ dies. The maximum lifetime of the FDN, HDN and residual energy after both of them are used as the optimization objective. 
Table 1: Network Parameters

\begin{tabular}{|l|c|}
\hline \multicolumn{1}{|c|}{ Parameter name } & Value \\
\hline \multirow{2}{*}{ The area of network } & $30 \mathrm{~m} * 30 \mathrm{~m}$ \\
\cline { 2 - 2 } The number of wireless sensors & $100 \mathrm{~m} * 100 \mathrm{~m}$ \\
\cline { 2 - 2 } & 30 \\
\hline Energy transmitting circuit & $50 \mathrm{~nJ} / \mathrm{bit}$ \\
\hline The initial energy of nodes & $0.1 \mathrm{~J}$ \\
\hline $\begin{array}{l}\text { Energy consumption of signal } \\
\text { amplification under the free space of unit } \\
\text { data }\end{array}$ & $10 \mathrm{pJ} / \mathrm{bit} / \mathrm{m} 2$ \\
\hline $\begin{array}{l}\text { Energy consumption of signal } \\
\text { amplification in multiple path attenuation } \\
\text { of unit data }\end{array}$ & \begin{tabular}{c}
$0.0013 \mathrm{pJ} / \mathrm{bit} / \mathrm{m} 4$ \\
\hline Data fusion energy
\end{tabular} \\
\hline ETX Transmit energy & $\begin{array}{c}50 * 0 \mathrm{~nJ} / \mathrm{bit} / \mathrm{message} \\
\mathrm{J} / \mathrm{bit}\end{array}$ \\
\hline ERX Receive energy & $\begin{array}{c}50 * 00000000001 \\
\mathrm{~J} / \mathrm{bit}\end{array}$ \\
\hline
\end{tabular}

The following Table 2 shows the improvement ratio of the LEACH protocol when the cluster contains $\mathrm{CH}$ and ViceCH. In LEACH-G, the $\mathrm{CH}$ always gets data from nodes, aggregates this data and sends it to the $\mathrm{SN}$. The $\mathrm{CH}$ will die earlier than the other nodes in the cluster because of its operation of receiving and sending. When the $\mathrm{CH}$ dies, the cluster will become useless because the data gathered by cluster nodes will never reach the SN. In LEACH-GV protocol, in addition to having a $\mathrm{CH}$ in the cluster, there is a vice- $\mathrm{CH}$ that takes the role of the $\mathrm{CH}$ when the $\mathrm{CH}$ dies. Hence, there is no need for cluster nodes to communicate with the SN directly; and consequently, this will extend the overall network lifetime.

Table 2: The Improvement Ratio LEACH-G and LEACH-GV

\begin{tabular}{|c|c|c|c|}
\cline { 2 - 4 } \multicolumn{1}{c|}{} & LEACH-G & LEACH-GV & $\begin{array}{c}\text { The improvement } \\
\text { rate of performance }\end{array}$ \\
\hline FDN & 226.4 & 221.4 & $-2 \%$ \\
\hline $\begin{array}{c}\text { Residual } \\
\text { Energy after } \\
\text { FDN }\end{array}$ & 0.571798 & 0.966341 & $69 \%$ \\
\hline HDN & 289.2 & 358.35 & $23.90 \%$ \\
\hline $\begin{array}{c}\text { Residual } \\
\text { Energy after } \\
\text { HDN }\end{array}$ & 0.105977 & 0.121772 & $14.90 \%$ \\
\hline
\end{tabular}

The following Table 3 shows the improvement ratio between LEACH-V and LEACH-GV protocols, the difference between these protocols are in a $\mathrm{CH}$ selection matrix, in LEACH-V protocol the residual energy, distance from SN and the density of nodes, is set to select $\mathrm{CH}$, but in LEACH$\mathrm{GV}$ the residual energy, distance from $\mathrm{SN}$, is set to select $\mathrm{CH}$. As discussed earlier in a section, each factor affected energy consumption in a specific ratio, and each of these factors has its own ratio.
Table 3: The Improvement Ratio LEACH-V and LEACH-GV

\begin{tabular}{|c|c|c|c|}
\cline { 2 - 4 } \multicolumn{1}{c|}{} & $\begin{array}{c}\text { LEACH- } \\
\mathrm{V}\end{array}$ & LEACH-GV & $\begin{array}{c}\text { The improvement } \\
\text { rate of performance }\end{array}$ \\
\hline FDN & 212.5 & 221.4 & $4 \%$ \\
\hline $\begin{array}{c}\text { Residual } \\
\text { Energy after } \\
\text { FDN }\end{array}$ & 0.786337 & 0.966341 & $22 \%$ \\
\hline HDN & 305.95 & 358.35 & $17 \%$ \\
\hline $\begin{array}{c}\text { Residual } \\
\text { Energy after } \\
\text { HDN }\end{array}$ & 0.118723 & 0.121772 & $2.5 \%$ \\
\hline
\end{tabular}

The improvement ratio that shows in above table return to given weight for only for factors that affected in more ratio in energy consumption, which means any weight that we will give it for density will affect in negative if the other factors have affected in consumption of energy in a more ratio than density. Then the improvement ratio of LEACH-GV returns for this reason.

Table 4: The Improvement Ratio LEACH-G and LEACH-V

\begin{tabular}{|c|c|c|c|}
\hline & LEACH-G & LEACH-V & $\begin{array}{l}\text { The improvement } \\
\text { rate of performance }\end{array}$ \\
\hline FDN & 226.4 & 212.5 & $-6 \%$ \\
\hline $\begin{array}{c}\text { Residual } \\
\text { Energy after } \\
\text { FDN }\end{array}$ & 0.571798 & 0.786337 & $37.50 \%$ \\
\hline HDN & 289.2 & 305.95 & $5.70 \%$ \\
\hline $\begin{array}{c}\text { Residual } \\
\text { Energy after } \\
\text { HDN }\end{array}$ & $\begin{array}{l}0.1059 \\
77\end{array}$ & 0.118723 & $12 \%$ \\
\hline
\end{tabular}

The above Table 4 shows the improvement ratio between LEACH-G and LEACH-V protocols. The differences between these protocols are in a $\mathrm{CH}$ selection matrix, and the presence of vice node. As discussed in the above section how these factors affected the lifetime.

\section{CONCLUSION}

This paper proposes enhanced protocols; which are concerned with energy consumption, and both of them are improved on the LEACH protocol. The improvement is concerned with the $\mathrm{CH}$ selection mechanism and routing of packets, the basic protocol of this paper is LEACH-GV protocol. It selected $\mathrm{CH}$ which depends on high residual energy and distance from $\mathrm{CH}$ using GA to determine the weight value for each criterion, in addition to the presence of vice for each $\mathrm{CH}$. This protocol contributed to the achievement of a significant proportion of its purpose, where prolonged the lifetime of $\mathrm{HDN}$ is $23.90 \%$, and the improvement of the residual energy after $\mathrm{HDN}$ is $14.90 \%$, and the improvement of the residual energy after FDN is $69 \%$, but it did not achieve its purpose to extend the lifetime of FDN, where improvement was a negative $2 \%$, compared with LEACH-G protocol. 


\section{REFERENCES}

[1] Chiara Buratti, Andrea Conti, Davide Dardari and Roberto Verdone. 2009. "An Overview on Wireless Sensor Networks Technology and Evolution". Sensors, Vol. 9, No. 9, pp 6869-6896.

https://doi.org/10.3390/s90906869

[2] Richard William Skowyra. 2009. "A Centralized Energy Management System for Wireless Sensor Networks". Master thesis, Worcester Polytechnic Institute, Department of Computer Science.

[3] Wendi Rabiner Heinzelman, Anantha Chandrakasan, Hari Balakrishnan. 2000,"Energy-Efficient Cluster Head Selection in Clustering Routing for Wireless Sensor Networks".System Sciences, 2000. Proceedings of the 33rd Annual Hawaii International Conference, IEEE.

[4] Al $\square$ Karaki JN, Kamal AE. Routing techniques in wireless sensor networks: a survey. IEEE Wireless Comm. 2004;11(6):6 $\square 28$.

https://doi.org/10.1109/MWC.2004.1368893

[5] Singh SK, Singh MP, Singh DK. A survey of energy $\square$ efficient hierarchical cluster $\square$ based routing in wireless sensor networks. Int $\mathbf{J}$ Adv NetwAppl (IJANA). 2010;2(02):570 $\square 580$.

[6] Liu Y, Xu K, Luo Z, Chen L. A reliable clustering algorithm base on LEACH protocol in wireless mobile sensor networks. In: Mechanical and Electrical Technology (ICMET), 2010 2nd International Conference on, IEEE; 2010: 692 $\square 696$.

[7] Liu J-L, Ravishankar CV. LEACH-GA: genetic algorithm-based energy-efficient adaptive clustering protocol for wireless sensor networks. Int J Mach Learn Comput. 2011;1(1):79

https://doi.org/10.7763/IJMLC.2011.V1.12

[8] Rajashree .V.Biradar, V.C.Patil, Dr S. R. Sawant, Dr R. R. Mudholkar, "Classification and comparison of routing protocols in wireless sensor networks", Ubiquitous Computing Security Systems journals

[9] Akkaya, K. and Younis, M. 2005. "A Survey of Routing Protocols in Wireless Sensor Networks". Elsevier Ad Hoc Network, pp 325-349.

https://doi.org/10.1016/j.adhoc.2003.09.010

[10] Karthika Sundaran, Velappa Ganapathy and Priyanka Sudhakara, "Fuzzy Logic Based Unequal Clustering in Wireless Sensor Network for Minimizing Energy Consumption", 2017 Second International Conference On Computing and Communications Technologies(ICCCT'17), pp. 304-309

https://doi.org/10.1109/ICCCT2.2017.7972283 